\title{
The effect of alcoholic extract of Silybum marianum leaves against some of Rhizoctonia solani strains
}

\begin{abstract}
The antifungal activity of ethanol extract of Silybum marianum was investigated in-vitro against three strains of Rhizoctonia solani at different concentrations (5, 10, 15 and 20\%). Bioassay of extract was conducted by poisoned food technique with three replications. The findings showed that strain of $R$. solani (Eggplant) was susceptible to concentrations of S. marianum more than other strains in mycelial growth and inhibition percentage of fungal growth $(3.9 \mathrm{~cm}, 56.4 \%)$ respectively whereas means of concentrations resulted to reduce the fungal growth gradually with increase concentration of $S$. marianum $(5.7,4.4$, 4.3 and $1.6 \mathrm{~cm})$ for concentrations of $(5,10,15$ and $20 \%)$ respectively, A concentration of $20 \%$ was recorded maximum of inhibition percentage of mycelial growth of $R$. solani strains $82.2 \%$ followed by concentrations of 15,10 and $5 \%$ that recorded $52.2,50.3$ and $36.2 \%$ respectively. The interaction between concentrations of $\mathrm{S}$. marianum with strains of $R$ solani was showed significantly differences between them in mycelial growth and inhibition percentage of fungal growth for all $R$. solani strains.
\end{abstract}

Volume 5 Issue 3 - 2017

\author{
Hussein Ali Salim,' Mohammed Nadeem \\ Kasim Hantoosh, ${ }^{2}$ Firas Tariq Rashid,' Nadir \\ Flayh Ali \\ 'Ministry of Agriculture, Iraq \\ ${ }^{2}$ College of Agriculture, University of Diyala, Iraq
}

Correspondence: Hussein Ali Salim, Ministry of Agriculture, Baqubah-Diyala-Iraq, Iraq, Tel +96470753232I, Email h_salimIIIII@@yahoo.com

Received: August 04 2017| Published: August 22, 2017

Keywords: silybum marianum, rhizoctonia solan, poisoned food technique

\section{Introduction}

$R$. solani is the most widely known and most studied species of genus Rhizoctonia. It was originally described by Julius Kühn from potato in $1858 .{ }^{1} R$. solani is soilborne Basidiomycete occurring worldwide. Its highly destructive lifestyle as a non-obligate parasite causes necrosis and damping-off on numerous host plant species. Because of the lack of conidia, $R$. solani exists as vegetative hyphae and sclerotia in nature. Sclerotia are an encapsulated, tight hyphal clump that protects and preserves the fungus over non-optimal times. The fungus is dispersed mainly via sclerotia, contaminated plant material or soil spread by wind, water or during agricultural practices such as tillage and seed transportation. ${ }^{2}$ Phytopathogenic fungi are controlled by synthetic fungicides; however, the use of these is increasingly restricted due to the harmful effects of pesticides on the environment. ${ }^{3}$ Continuous application of such chemicals has negative impacts on human health and destruction of the ecosystem that results in new strains of pathogens that are more resistant and difficult to control. ${ }^{4}$ It has become necessary to adopt eco-friendly approaches for better crop health and for yield. In the past, several higher plants have proved their usefulness against a number of fungi. ${ }^{5}$ Plant extracts have the ability to inhibit mycelial growth in many fungal species. ${ }^{6-8}$ Silybum marianum (L), milk thistle, is an annual or biennial herb. It belongs to the family Asteraceae. ${ }^{9}$ The plant is known for its medicinal properties having important chemical constituents including several flavonolignans collectively known as silymarin that has antioxidant properties. ${ }^{10}$ In the present study, the antifungal activity of leaves extract of $S$. marianum was tested in vitro against the $R$. solani strains that isolated from the plants (tomato, eggplant, and cauliflower).

\section{Materials and methods}

A laboratory experiment was carried out in a college of agriculture, university of Diyala during 2016 .The $S$. marianum leaves were collected from orchard located in Baqubah city, R. solani strains were isolated from infected plants (tomato, eggplant and cauliflower). Leaves of $S$. marianum were thoroughly washed under tap water to remove dust and other impurities then dried and powdered with the help of a blender to a fine powder, $250 \mathrm{gm}$ powder was soaked with $500 \mathrm{ml}$ of ethanol for preparing the alcoholic extract and kept on shaker about 24hour for continuous stirring, the extract was filtered by double layered muslin cloth and the extracts were centrifuged at $3000 \mathrm{rpm}$ for 10 minutes. Supernatant was dried by oven at $40^{\circ} \mathrm{C}$ to evaporate the solvent and it was turned to solid. Concentrations of extract 5, 10, 15, 20\% were prepared and poured into Petri dishes by poison food technique, ${ }^{11}$ then allowed to solidify. The Petri dishes were inoculated with the pathogen by transferring five $\mathrm{mm}$ diameter agar disc from the fresh cultures. Three replications were maintained for each treatment. The basal medium (PDA) without any plant extract served as the control, all the inoculated Petri dishes were incubated at $25 \pm 1{ }^{\circ} \mathrm{C}$ for seven days. The cross diameters of colony growth of test fungus was measured in all the treatments and compared with the control. The percent inhibition of fungal growth was estimated by using following formula. ${ }^{12}$

$$
\mathrm{I}=\frac{\mathrm{C}-\mathrm{T}}{\mathrm{C}} \mathrm{X} 100
$$

Where, $\mathrm{I}=$ percent inhibition, $\mathrm{C}=$ Colony diameter in control and $\mathrm{T}=$ Colony diameter in treatment.

The experiment was conducted in Factorial Experiments and the data was analyzed by one way Analysis of Variance (ANOVA). ${ }^{13}$

\section{Results and discussion}

The data revealed that means of $R$. solani strains were significantly difference in mycelial growth of $R$. solani at all tested concentrations of $S$. marianum, $R$. solani (Eggplant) was susceptible to concentrations of $S$. marianum more than other strains $(3.9 \mathrm{~cm})$ whereas means of concentrations resulted to reduce the fungal growth gradually with increase concentration of $S$. marianum $(5.7,4.4,4.3$ and $1.6 \mathrm{~cm})$ for concentrations of $(5,10,15$ and $20 \%)$ respectively, interaction between concentrations of $S$. marianum with strains of $R$. solani was 
significantly difference in reduction of fungal growth of $R$. solani (Table 1 \& Figures 1-3). R. solani (Eggplant) was susceptible to concentrations of $S$. marianum in inhibition percentage of fungal growth at (56.4\%) followed by $R$. solani (Tomato) $43.5 \%$ and $R$. solani (cauliflower) $32.6 \%$, concentrations of $S$. marianum showed significant activities in percent inhibition of fungal growth of $R$. solani . A concentration of $20 \%$ was recorded maximum of inhibition percentage of mycelial growth of $R$. solani strains $82.2 \%$ followed by concentrations of 15,10 and $5 \%$ that recorded $52.2,50.3$ and $36.2 \%$ respectively. The interaction between concentrations of $S$. marianum with strains of $R$. solani was showed significantly differences between them (Table 2).

Table I In vitro efficacy of ethanol extract of different concentrations of S. marianum on fungal growth of $R$. solani strains

\begin{tabular}{|c|c|c|c|c|c|c|}
\hline \multirow{2}{*}{ Strains of $R$. solani } & \multicolumn{5}{|c|}{ Concentrations of Silybum marianum } & \multirow{2}{*}{ Means of strains $(\mathrm{cm})$} \\
\hline & $5 \%$ & $10 \%$ & $15 \%$ & $20 \%$ & Control & \\
\hline R. solani (Tomato) & 5.2 & 5 & 4.9 & 1.3 & 9 & 5 \\
\hline R. solani (Eggplant) & 5.4 & 2 & 1.8 & 1.4 & 9 & 3.9 \\
\hline R. solani (cauliflower) & 6.6 & 6.4 & 1.8 & 2.1 & 9 & 6 \\
\hline Means of Concentrations (cm) & 5.7 & 4.4 & 4.3 & 1.6 & 9 & \\
\hline
\end{tabular}

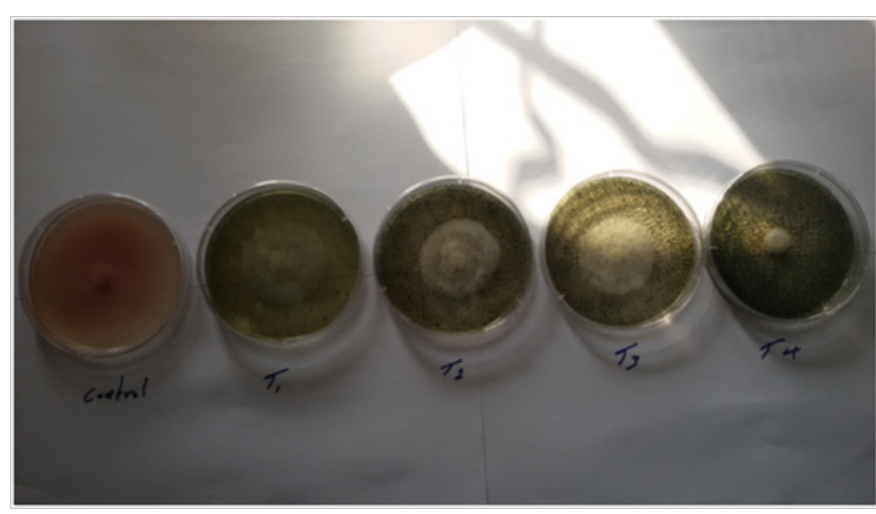

Figure I Efficacy of ethanol extract of different concentrations of S. marianum on R. solani (Tomato).

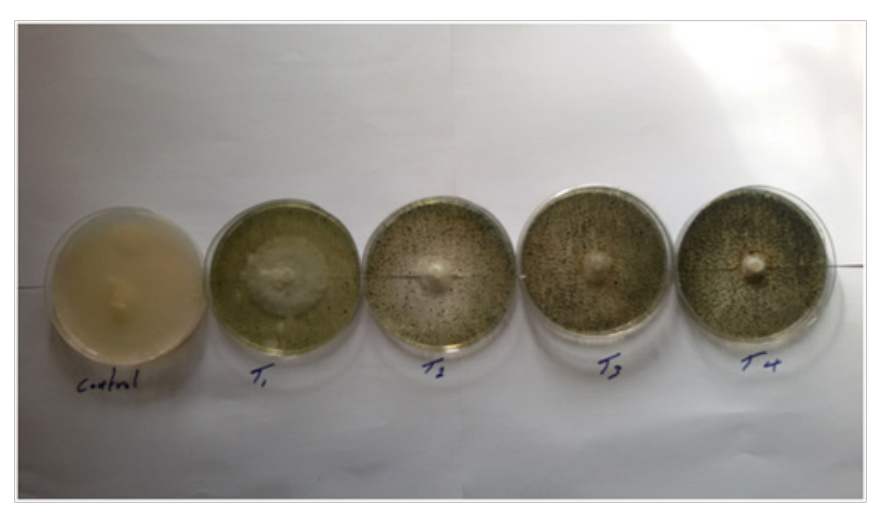

Figure 2 Efficacy of ethanol extract of different concentrations of S. marianum on $R$. solani (Eggplant).

Table 2 In vitro efficacy of ethanol extract of different concentrations of S. marianum in percent inhibition of fungal growth of R. solani strains

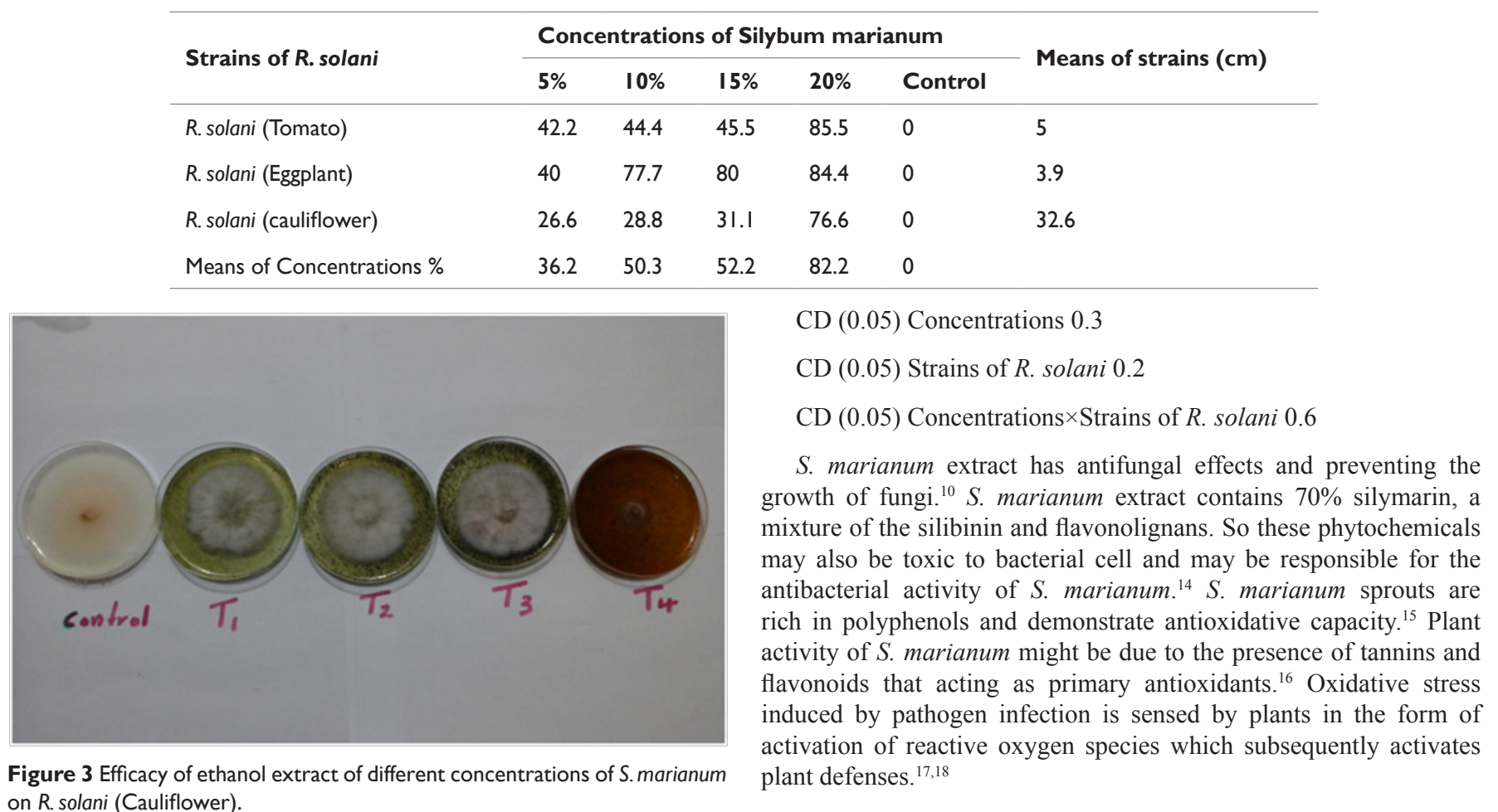

on R. solani (Cauliflower). 
Rate of inhibition

$\mathrm{CD}(0.05)$ Concentrations 0.9

CD (0.05) Strains of $R$. solani 0.7

$\mathrm{CD}(0.05)$ Concentrations $\times$ Strains of $R$. solani 1.6

\section{Conclusion}

Under in vitro conditions, the strains of $R$. solani were well controlled by ethanol extract of $S$. marianum by different concentrations. This extract showed maximum activity; even at very low concentrations. The extract of $S$. marianum could be considered as potential source of antifungal compound for treating $R$. solani strains. We conclude from that this extract exhibit fungicidal properties that support their use as antiseptics. These need to be further evaluated under in vivo conditions so as to make minimum use of chemicals.

\section{Acknowledgements}

None.

\section{Conflict of interest}

The author declares no conflict of interest.

\section{References}

1. Kühn J. Die Krankenheiten der Kulturwachse, ihre Ursachen und ihre Verhutung. Germany: Gustav Bosselman; 1858. 312 p.

2. Deacon JW. Translocation and transfer in Rhizoctonia: mechanism and significance. In: Sneh B, Jabaji-Hare S, editors. Rhizoctonia species:taxonomy, molecular biology, ecology, pathology and disease control. Netherlands: Kluwer Academic Publishers; 1996. p. 117-125.

3. Harris CA1, Renfrew MJ, Woolridge MW. Assessing the risk of pesticide residues to consumers: recent and future developments. Food Addit Contam. 2001;18(12):112 4-1129.

4. Khalil AB, Dabaneh BF, Anfoka GH. Antifungal Activity of Medicinal Plants from Jordan Environment. Plant Pathol J. 2005;4(2):130-132.

5. Anil S, Saroj A, Parminder K. Evaluation of plant extracts against Rhizoctonia solani causing sheath blight of rice. The Journal of Plant Protection Sciences. 2009;1(1):25-30.
6. Guerin JC, Reveille HP. Antifungal activity of plant extracts used in therapy. I. Study of 41 plant extracts against 9 fungi species. Annales Pharmaceutiques Francaises. 1984;42:553-559.

7. Natarajan MR, Lalithakumari D. Antifungal activity of the leaf extracts of Lawsonia inermis on Drechslera oryzae. Indian Phytopathology. 1987;40:390-395.

8. Singh RK, Dwivedi RS. Effect of oils on Sclerotium rolfsii causing footrot of barley. Indian Phytopathology. 1987;40:531-533.

9. Nasir YJ. Flora of Pakistan: Asteraceae. Islamabad: National Herbarium Pakistan Agriculture Research Council; 1990. 192:59-117.

10. Salehi M, Hasanloo T, Mehrabian S, et al. Effects of Silybum marianum (L.) Gaertn seeds extract on dermatophytes and saprophytes fungi in vitro compare to clotrimazol. Pharmaceutical Sciences. 2011;16(4):203-210.

11. Nene VL, Thaplyal PN. Fungicides in Plant Disease Control. India: Oxford \& IBH Publ. Co. Pvt. Limited; 1987. 507 p.

12. Vincent JM. Distribution of fungal hyphae in the presence of certain inhibitors. Nature. 1947;15:850.

13. Fisher RA, Yates. A statistical method for research workers. UK: Oliver and boyd ltd; $1968.10 \mathrm{p}$.

14. Amoos Bajwa, Sheraz Tariq, Alamgeer Yuchi, et al. Evaluation of antibacterial activity of Silybum marianum against pathogenic and resistant bacteria. European journal of medicinal plants. 2016;13(4):1-7.

15. McDonald S, Prenzler PD, Antolovich M, et al. Phenolic content and antioxidant activity of olive extracts. Food Chem. 2001;73:73-84.

16. Kousara S, Hicksb LM, Sheikha MA, et al. Bioactive potential of stress induced extracts of silybum marianum. Biological and biochemical oxidation processes. 2015;38(4):1678-1689.

17. Bolwell GP, Bindschedler LV, Blee KA, et al. The Apoplastic Oxidative Burst in Response to Biotic Stress in Plants: A Three Component System. J Exp Bot. 2002;53(372):1367-1376.

18. Sayyah M, Boostania H, Paksereshta S, et al. Comparison of Silybum marianum(L.). Gaertn. With fluoxetine in the treatment of ObsessiveCompulsive Disorder. Prog Neuropsychopharmacol Biol Psychiatr. $2011 ; 35(4): 887-895$ 